\title{
A APOSENTADORIA DO PROFESSOR DE EDUCAÇÃO BÁSICA NA LEGISLAÇÃO PREVIDENCIÁRIA BRASILEIRA
}

\author{
THE RETIREMENT OF THE TEACHER IN BRAZILIAN SOCIAL SECURITY \\ LEGISLATION
}

\author{
Wilton Antônio Machado Junior ${ }^{1}$
}

\section{RESUMO}

O Brasil passa por momentos instáveis que acarretam desequilíbrios em todas as esferas, a política não fica fora desse cenário. O "rombo" da previdência social é um assunto reiteradamente discutido na esfera política, empresarial e pela mídia. Em função disso, nota-se a preocupação da sociedade com a sua futura aposentadoria. $O$ objetivo deste artigo foi mostrar os requisitos e a evolução histórica da legislação em torno da aposentadoria de professor de educação básica no Regime Geral de Previdência Social. E, também, diferenciar a aposentadoria comum no Regime Geral de Previdência Social e a aposentadoria vinculada aos professores da educação básica. Como metodologia, foi adotada a pesquisa bibliográfica e documental por meio da leitura crítica de obras pertinentes ao enfrentamento do tema. Os professores de ensino básico que estão vinculados ao Regime Geral de Previdência Social e requerem a aposentadoria por tempo de contribuição tem direito a aposentadoria 5 anos antes do estipulados para os outros contribuintes; e, apenas os professores básica que exercem a profissão dentro da sala de aula, direção e assessoramento gozam do benefício de aposentadoria com a diminuição de 5 anos.

Palavras-chave: Previdência Social; Regime Geral da Previdência Social; Aposentadoria de Professor; Aposentadoria Especial.

1 Mestrando em Desenvolvimento, Tecnologias e Sociedade pela Universidade Federal de Itajubá (UNIFEI), especialista em Direito Constitucional pela Faculdade de Ciências Humanas de Cruzeiro (FACIC), especialista em Tecnologias, Formação de Professores e Sociedade pela Universidade Federal de Itajubá (UNIFEI), Bacharel em Direito pela Faculdade de Ciências Humanas de Cruzeiro FACIC) e Tecnólogo em Gestão Empresarial pela Faculdade de Tecnologia do Estado de São Paulo (FATECUnidade Cruzeiro). Universidade Federal de Itajubá/ Instituto de Engenharia de Produção - Avenida BPS, 1303, Bairro Pinheirinho - CEP: 37500-903 - Itajubá-MG, Brasil. 


\section{ABSTRACT}

Brazil is going through unstable moments that imply imbalances in all spheres, politics is not outside this scenario. The "gap" of social security is a subject repeatedly discussed in the political, business and media sphere. As a result, the company's concern about its future retirement is noteworthy. The purpose of this article was to present, in a general way, the attributions and characteristics of general retirement and special retirement. As a methodology, the bibliographical and documentary research was adopted by means of the critical reading of research pertinent to the confrontation of the theme. Teachers who are linked to the General Social Security System and require retirement for contribution time are entitled to retirement 5 years earlier than stipulated for other taxpayers; and only the basic professors who carry out the career within the classroom, direction and counseling enjoy the retirement benefit with the decrease of 5 years.

Keywords: Social Security; Social Security System; Teacher Retirement; Special Retirement.

\section{INTRODUÇÃO}

$\mathrm{Na}$ atual situação política e econômica que o Brasil atravessa, a aposentadoria tem sido uns dos assuntos mais discutidos em função, principalmente, das reformas e projetos de reforma que tramitam no Congresso Nacional.

Neste contexto, esta pesquisa concentra-se na aposentadoria dos professores de educação básica que, em razão da sua função, contemplam um período menor para aposentar, tanto mulheres como homens.

Como problema de pesquisa, tem-se: quais são as peculiaridades da aposentadoria dos professores em comparação com a aposentadoria comum no regime geral da Previdência Social?

Acredita-se que os professores de ensino básico que estão vinculados ao Regime Geral de Previdência Social e requerem a aposentadoria por tempo de contribuição tem direito a aposentadoria 5 anos antes do estipulados para os outros contribuintes. Além disso, considera-se, também, que apenas os professores da educação básica que exercem a profissão dentro da sala de aula, direção e assessoramento gozam do benefício de aposentadoria com a diminuição de 5 anos. 
Neste artigo, o objetivo é mostrar os requisitos e a evolução histórica da legislação em torno da aposentadoria de professor de educação básica no Regime Geral de Previdência Social. E, também, diferenciar a aposentadoria comum no Regime Geral de Previdência Social e a aposentadoria vinculada aos professores da educação básica.

Como metodologia, foi adotada a pesquisa bibliográfica e documental. Procedeuse a leitura crítica, a redação de resumos e paráfrases das obras pertinentes ao enfrentamento do tema e à comprovação das hipóteses. Além da leitura de livros pertinentes ao objeto de pesquisa (a aposentadoria do professor de educação básica na legislação previdenciária brasileira), serão consultados documentos disponíveis online, devidamente referenciados nas Referências.

\section{REGIMES PREVIDENCIÁRIOS E BENEFÍCIOS}

Nos dias atuais, no campo jurídico brasileiro, tem-se dois regimes previdenciários, o Regime Geral de Previdência Social e o Regime Próprio de Previdência Social.

De acordo com o artigo 201, da Constituição Federal, redação dada pela Emenda Constitucional $n^{\circ} 20$, "a previdência social será organizada sob a forma de regime geral, de caráter contributivo e de filiação obrigatória, observados critérios que preservem o equilíbrio financeiro e atuarial" (BRASIL, 1998, p. 1).

Nem todas os trabalhadores são cobertos pela Previdência Social, em especial no Regime Geral de Previdência, como citam Castro e Lizzari (2014, p. 66), são os casos dos:

Os servidores públicos civis, regidos por sistema próprio de previdência; os militares; os membros do Poder Judiciário e do Ministério Público; e os membros do Tribunal de Contas da União, todos por possuírem regime previdenciário próprio; e os que não contribuem para nenhum regime, por não estarem exercendo qualquer atividade. 
Assim, os trabalhadores que não estão inclusos no Regime Geral podem estar presentes no Regime Próprio ou, até mesmo, não contribuir de nenhuma forma para a Previdência Social.

O Regime Geral de Previdência Social (RGPS) contempla, de acordo com Castro (2014, p. 109):

os trabalhadores que possuem relação de emprego regida pela Consolidação das Leis do Trabalho (empregados urbanos, mesmo os que estejam prestando serviço a entidades paraestatais, os aprendizes e os temporários), pela Lei $n$. 5.889/73 (empregados rurais) e pela Lei n. 5.859/72 (empregados domésticos); os trabalhadores autônomos, eventuais ou não; os empresários, titulares de firmas individuais ou sócios gestores e prestadores de serviços; trabalhadores avulsos; pequenos produtores rurais e pescadores artesanais trabalhando em regime de economia familiar; e outras categorias de trabalhadores, como garimpeiros, empregados de organismos internacionais, sacerdotes, etc.

Assim, os trabalhadores da iniciativa privada estariam todos envolvidos neste tipo de regime previdenciário, são diversas as categorias que se enquadram nesses termos. Os que não estão contemplados pelo regime geral fazem parte do Regime Próprio de Previdência Social (RPPS).

São inúmeros regramentos que se enquadram no regime próprio, e existem algumas distinções importantes em relação ao regime geral, tais como a fixação da base de cálculo dos proventos tendo como base a última remuneração do servidor e a regra da paridade que corrige o valor dos proventos de acordo com o pago para os servidores ativos (CASTRO e LAZZARI, 2014, p. 111).

Cabe ainda expor outros dois institutos, que são igualmente relevantes, o Regime Previdenciário Complementar e o Regime dos Militares das Forças Armadas.

O primeiro, prevê a forma fechada e a aberta de previdência complementar privada, as fechadas são as caracterizadas em forma de fundação ou sociedade civil, sem fins lucrativos. 
Esta forma de previdência, segundo Castro e Lazzari (2014, p. 113), é "exclusivamente a empregados de uma empresa ou grupo de empresas, aos servidores dos entes públicos da Administração".

Ressalta-se que o próprio empregador não pode explorar este tipo de atividade de previdência complementar, sendo necessário criar uma entidade própria pra este fim.

Em outro sentido, a entidade aberta de previdência privada, segundo Castro e Lazzari (2014, p. 113) é

aquela que se enquadra na hipótese anterior. São instituições financeiras que exploram economicamente o ramo de infortúnios do trabalho, cujo objetivo é a instituição e operação de planos de benefícios de caráter previdenciário em forma de renda continuada ou pagamento único, constituídas unicamente sob a forma de sociedades anônimas.

Neste tipo de plano, o trabalhador pode entrar de forma voluntária, bastando preencher os requisitos da empresa, como estar formalmente no mercado de trabalho, entre outros aspectos.

Cabe destacar também o Regime dos Militares das Forças Armadas, eles não são considerados mais servidores públicos, eles recebem tratamento diferenciado, exigindo que a passagem para a inatividade, para a reserva, seja de acordo com o previsto nos $\S 7^{\circ}$ e $\S 8^{\circ}$ do artigo 40 , Constituição Federal.

Observa-se, assim, o destaque da EC $n^{\circ} 20$ ao regime geral, que tem dois aspectos, contributivo e de filiação obrigatório.

Segundo Santos (2013, p. 191), o caráter contributivo é devido a:

cobertura previdenciária pressupõe o pagamento de contribuições do segurado para a custeio do sistema. Somente quem contribui adquire a condição de segurado da Previdência Social e, cumpridas as respectivas carências, tem direito à cobertura previdenciária correspondente à contigência-necessidade que $o$ acomete. 
Assim, para ser segurado é obrigatória a contribuição, pois o Previdência é custeada, principalmente, pelos seus segurados, em contrapartida, há benefícios aos seus contribuintes.

Ressalta-se que os benefícios não podem ser inferior ao valor do salário mínimo

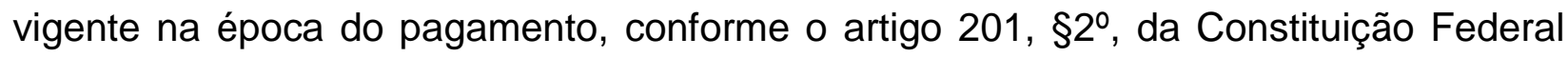
(BRASIL, 2014):

Art. 201. A previdência social será organizada sob a forma de regime geral, de caráter contributivo e de filiação obrigatória, observados critérios que preservem o equilíbrio financeiro e atuarial, e atenderá, nos termos da lei, a:

(...)

$\S$ 2ํ№nhum benefício que substitua o salário de contribuição ou o rendimento do trabalho do segurado terá valor mensal inferior ao salário mínimo.

Assim, para não desvalorizar o benefício obtido pelos segurados ou seus dependentes, os valores devem ser reajustados periodicamente.

Os segurados são sujeitos ativos da relação jurídica cujo objeto seja o oferecimento de prestação de natureza previdenciária.

Conforme 0 art. $1^{\circ}$, da Lei n. 8.213/91 cabe à Previdência Social assegurar aos seus beneficiários, "meios indispensáveis de manutenção, por motivo de capacidade, desemprego involuntário, idade avançada, tempo de serviço, encargos familiares e prisão ou morte daqueles de quem dependiam economicamente".

Cabe destacar que os servidores titulares de cargos em comissão, que não são titulares de cargos efetivos, desde a EC 20/98 estão excluídos do regime próprio de previdência dos servidores públicos (SANTOS, 2013, p. 204).

Como estes funcionários não podem ficar sem proteção previdenciária, em função disso, são mantidos como segurados obrigatórios do regime geral da previdência social.

\section{APOSENTADORIA POR TEMPO DE CONTRIBUIÇÃO}


A aposentadoria por tempo de contribuição é um benefício previdenciário feito ao segurado ao longo de sua vida laboral e está prevista no artigo 201, §7º, inciso I, da Constituição Federal, em que diz "é garantida ao segurado que completar 35 anos de contribuição, se homem, e 30, se mulher".

Assim, nota-se há a separação etária entre homens e mulheres, sendo o período de trabalho da mulher sendo cinco anos inferior ao homem, mas estes números podem ter redução maior ainda dependendo do tipo de aposentadoria, tal como ocorre com o professor.

Umas das discussões existentes na doutrina era quanto a perda da qualidade de segurado, algo que leva a pessoas, muitas vezes, a não serem comtempladas por um benefício.

Segundo o artigo 201, §1ํㅡㄹ da Lei 8.213:

Assim, a perda da qualidade de segurado não prejudica o direito à aposentadoria para cuja concessão tenham sido preenchidos todos os requisitos, segundo a legislação em vigor à época em que estes requisitos foram atendidos.

Houve a preocupação de deixar bem claro a necessidade de resguardar os direitos adquiridos dos trabalhadores, não seria justo não contemplar o segurado que já adquiriu um direito.

Conforme Santos (2013, p. 374) expõe:

Trata-se de norma que respeita o direito adquirido do segurado e que terá reflexo na cobertura previdenciária até para seus dependentes. Não teria sentido que, cumpridos os requisitos para se aposentar, deixando o segurado de contribuir e perdendo essa condição, perdesse o direito ao benefício.

Ressalta-se ao exposto acima, quando há o direito adquirido pelo segurado, a qualquer tempo ele pode solicitar a aposentadoria, porque lhe é de direito e não pode ser revogado. 
Na mesma direção, o artigo $3^{\circ}$ da Lei n. 10.666/2003 dispõe que "a perda da qualidade de segurado não será considerada para a concessão das aposentadorias por tempo de contribuição e especial".

Desta forma, nota-se que não é apenas a aposentaria por tempo de contribuição que não sofre com a perda da qualidade de segurado.

As leis previdenciárias sofreram grande alteração com a Emenda Constitucional n. 20 de 1998, em função disso, algumas pessoas adquiriram o direito ao benefício antes da entrada em vigência da EC. Nesse sentido, de acordo com artigo $3^{\circ}$, da EC 20/98: "poderão se aposentar, a qualquer tempo, os segurados que, até a data da publicação da Emenda, tenham cumprido todos os requisitos, com a aplicação das regras então vigentes.

Com todas as atualizações que as normas previdenciárias vem sofrendo com o passar dos anos, é importante evidenciar o período de transição necessário para adequação e entrada em vigência das novas normas.

Sendo assim, conforme o artigo $6^{\circ}$ da EC 20/98 "é garantido ao segurado que até o dia anterior à data de publicação desta Lei tenha cumprido os requisitos para a concessão de benefício o cálculo segundo as regras até então vigentes".

Assim, caso o segurado tenha adquirido o direito antes da Emenda Constitucional n. 20 de 1998, o segurado poderia se aposentar, contudo, quem completasse o tempo necessário para aposentar no dia da vigência da Lei, não conseguiria ter direito naquele momento ao benefício almejado.

$\mathrm{Na}$ transição proposta pela Emenda Constitucional n. 20, a aposentadoria proporcional foi atingida diretamente, como relata Castro e Lazzari (2014, p. 70):

este benefício corresponderá a $70 \%$ do salário de benefício calculado para a aposentadoria integral, acrescendo-se 5\% por ano adicional, até o limite de $100 \%$, regra que também passou a ser aplicada no serviço público. Anteriormente, a aposentadoria proporcional no serviço público era calculada tomando-se uma percentagem entre o tempo de serviço completado e o tempo necessário à aposentadoria integral. 
Assim, a EC n. 20 trouxe alterações importantes e também trouxe regramentos para quem está a beira de se aposentar com regras especificas nesse sentido, cabendo o trabalhador avaliar se era benéfico ou não.

\section{APOSENTADORIA DE PROFESSOR}

De acordo com a Fundação ANASPS (2007), em 1821 surgiu-se o que há no Brasil como legislação voltada para aposentadoria de professores, concedendo aos mestres professores com 30 anos de serviço o que chamamos hoje de aposentadoria.

Por meio do "Decreto das Jubilações dos Professores e Mestres Regios de Primeiras Letras, Grammatica Latina e Grega, Rhetorica e Filosofia" que tem a seguinte:

As Côrtes Geraes, Extraordinarias e Constituintes da Nação Portugueza, reconhecendo que um dos meios de promover a Instrucção Publica he contemplar as pessoas, que della são encarregadas: Decretão o seguinte: $1 .$.

Os Professores e Mestres Regios de um e outro sexo, de Primeiras Letras, Grammatica Latina e Grega, Rhetorica e Filosofia, que por espaço de trinta annos continuos, ou interpollados houverem regido louvavelmente, e sem nota, as suas respectivas Cadeiras, serão jubilados com o vencimento de todo o seu ordenado. [...] Paço das Côrtes em 29 de setembro de 1821 (ANASP, 2007, p. 1).

Posteriormente, seguindo a legislação, outra mudança fundamental foi trazida pela Lei Orgânica da Previdência Social, Lei oㅜ 3.807/60 em conjunto com o Decreto no $53.831 / 64$, que elencava a aposentadoria do professor de magistério como especial, enquadrando-a como atividade penosa.

Adiante, a Emenda $n^{\circ} 18$ de 1981 solidificou a regulação da aposentadoria, sendo de 30 anos para homens e 25 anos para as mulheres. Isso foi seguido pela Constituição de 1988. 
Nesse âmbito, enquadrava-se os professores da educação básica e do ensino superior, até entrar em vigor da Emenda Constitucional no 20 de 1998.

De acordo com Castro e Lazzari (2014, p. 560):

Pelo exercício das funções de magistério de qualquer nível (educação infantil, ensinos fundamental, médio e universitário), na condição de empregado, era assegurada a aposentadoria por tempo de serviço com renda mensal de $100 \%$ do salário de benefício, ao professor, após trinta anos, e à professora, após vinte e cinco anos, de efetivo exercício de função de magistério.

Assim, eram incluídas todas as categorias de professores para fator de aposentadoria especial, sendo considerado o período de 30 anos para homem e 25 anos para mulheres. Posteriormente, foram criados novos regulamentos que alteraram profundamente as legislações e a interpretação da mesma, como o caso dos professores universitários que foram retirados deste enquadramento.

Nos dias atuais, tem-se a regulamentação da aposentadoria dos professores por meio do artigo 201 da Constituição Federal de 1988.

Art. 201. A previdência social será organizada sob a forma de regime geral, de caráter contributivo e de filiação obrigatória, observados critérios que preservem o equilíbrio financeiro e atuarial, e atenderá, nos termos da lei, a:

(...)

$\S 8^{\circ}$ Os requisitos a que se refere 0 inciso I do parágrafo anterior serão reduzidos em cinco anos, para o professor que comprove exclusivamente tempo de efetivo exercício das funções de magistério na educação infantil e no ensino fundamental e médio.

Assim, no presente, tem-se que o professor, homem, pode se aposentar com 30 anos de contribuição, enquanto as mulheres, professoras, podem se aposentar com 25 anos de contribuição.

Nos aspectos infraconstitucionais, a aposentadoria é regulada pelo artigo 56 da Lei 8.213 de 1991:

Art. 56. O professor, após 30 (trinta) anos, e a professora, após 25 (vinte e cinco) anos de efetivo exercício em funções de magistério poderão aposentarse por tempo de serviço, com renda mensal correspondente a $100 \%$ (cem por 
cento) do salário-de-benefício, observado o disposto na Seção III deste Capítulo.

Desta forma, além do que é exposto pela Constituição Federal, tem-se o que está presente nos Planos de Benefícios da Previdência Social e dá outras providências.

De acordo com Martinez (2010, p. 873), "de modo geral, para fins previdenciários, professor é o educador que ministra aula na educação infantil, no ensino fundamental e médio".

Assim, nessa perspectiva, não se enquadra o professor universitário, eles são excluídos deste benefício e seguindo a norma geral. Contudo, na época foi criada uma

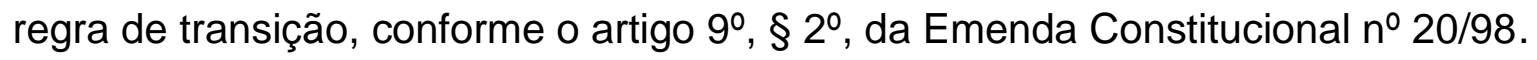

Na linha deste dispositivo legal, houve um bônus até a publicação da EC ํㅜ 20, sendo de $17 \%$ para homens e $20 \%$ para mulheres.

O artigo 56, $\S 2^{\circ}$, do Decreto ํo 3.048/99 define o que é função de magistério "(...) a atividade docente do professor exercida exclusividade em sala de aula". Em consonância, tem-se a Súmula oㅜ 726 do Supremo Tribunal Federal, de 2003, que diz "para efeito de aposentadoria especial de professores, não se computa o tempo de serviço prestado fora da sala de aula".

Esta dúvida pairou durante um tempo enorme na doutrina e na jurisprudência brasileira.

A Lei ํo 11.301 de 2006 que alterou o artigo 67, § 2º, da Lei de Diretrizes e Bases da Educação Nacional (Lei no 9.394 de 1996) cita o seguinte:

Art. $67, \S 2^{\circ}$. Para os efeitos do disposto no $\S 5^{\circ}$ do art. 40 e no $\S 8^{\circ}$ do art. 201 da Constituição Federal, são consideradas funções de magistério as exercidas por professores e especialistas em educação no desempenho de atividades educativas, quando exercidas em estabelecimento de educação básica em seus diversos níveis e modalidades, incluídas, além do exercício da docência, as de direção de unidade escolar e as de coordenação e assessoramento pedagógico. 
Desta forma, foi ampliada as atividades classificadas como a de professor, não se limitando mais exclusivamente à atividade desenvolvida em sala de aula, correpondendo agora a direção, coordenação e assessoramento pedagógico.

Assim como esta norma legal, o Supremo Tribunal Federal rege a seguinte jurisprudência:

AÇÃO DIRETA DE INCONSTITUCIONALIDADE MANEJADA CONTRA O ART. 10- DA LEI FEDERAL 11.301/2006, QUE ACRESCENTOU O § 2을 ART. 67 DA LEI 9.394/1996. CARREIRA DE MAGISTÉRIO. APOSENTADORIA ESPECIAL PARA OS EXERCENTES DE FUNÇÕES DE DIREÇÃO, COORDENAÇÃO E ASSESSORAMENTO PEDAGÓGICO. ALEGADA OFENSA AOS ARTS. 40, § 5, E 201, § 8ㅁ, DA CONSTITUIÇÃO FEDERAL. INOCORRÊNCIA. AÇÃO JULGADA PARCIALMENTE PROCEDENTE, COM INTERPRETAÇÃO CONFORME.

I - A função de magistério não se circunscreve apenas ao trabalho em sala de aula, abrangendo também a preparação de aulas, a correção de provas, o atendimento aos pais e alunos, a coordenação e o assessoramento pedagógico e, ainda, a direção de unidade escolar. II - As funções de direção, coordenação e assessoramento pedagógico integram a carreira do magistério, desde que exercidos, em estabelecimentos de ensino básico, por professores de carreira, excluídos os especialistas em educação, fazendo jus aqueles que as desempenham ao regime especial de aposentadoria estabelecido nos arts. 40, § 5ำ e 201, § 8o, da Constituição Federal. III - Ação direta julgada parcialmente procedente, com interpretação conforme, nos termos supra.

Assim, o entendimento corrobora o exposto pela LBD, em que especifica quais atividades são características da profissão de professor.

No mesmo sentido, seguindo a ADIN n. 3772-2, julgada em 2008 pelo Supremo Tribunal Federal:

PROFESSORES QUE EXERCEREM CARGOS DE DIREÇÃO PEDAGÓGICA PODERÃO TER APOSENTADORIA ESPECIAL. O Supremo Tribunal Federal (STF) concluiu hoje (29) o julgamento da Ação Direta de Inconstitucionalidade (ADI) 3772, proposta contra 0 artigo $1^{\circ}$ da Lei Federal 11.301/06, que estabeleceu aposentadoria especial para especialistas em educação que exerçam direção de unidade escolar, coordenação e assessoramento pedagógico. A decisão garantiu o benefício da aposentadoria especial às atividades em discussão, desde que exercidas por professores. A questão foi trazida a julgamento com a apresentação do voto-vista do ministro Eros Grau, que acompanhou a divergência inaugurada pelo ministro Ricardo Lewandowski. Eles, somados aos ministros Marco Aurélio, Celso de Mello, Cezar Peluso e Menezes Direito formaram maioria e votaram no sentido de dar interpretação 
constitucional que não retirasse o benefício da aposentadoria especial de outras categorias de profissionais da educação. "Interpreto esse texto de modo a afirmar que o tempo de serviço prestado pelo professor no exercício de função de direção de unidade escolar e de coordenação e assessoramento pedagógico não pode ser concebido como tempo de serviço fora da sala de aula", considerou o ministro Eros Grau em voto lido na sessão de hoje. Sobre a matéria, o relator, ministro Carlos Ayres Britto, já tinha se pronunciado. Ele afirmou que, ao tratar do benefício, a Constituição (parágrafo 5을 do artigo $40 \mathrm{e}$ parágrafo $8^{\circ}$ do artigo 201) utiliza a palavra professor e não o "fraseado aberto"profissionais da educação. Para ele, a Constituição Federal exige que o professor se dedique exclusivamente às funções de magistério para ter direito à aposentadoria especial. "Não quero esvaziar as salas de aula, quero que os professores se realizem na sua verdadeira vocação", disse. No entanto, Ayres Britto ficou vencido junto com os ministros Joaquim Barbosa e Cármen Lúcia Antunes Rocha, que votaram pela procedência total da ação. (29.10.2008. Decisão publicada no DJE n. 212, divulgado em 7.11.2008)

Deste modo, se observa que a própria divergência no Supremo Tribunal Federal, em que os ministros se contra argumentavam na busca por uma posição majoritária a ser proferida pelo Tribunal.

\section{ASPECTOS CONTROVERTIDOS}

De acordo com o artigo 37, XVI, da Constituição Federal de 1988, quando se relata sobre cargos públicos, quanto à acumulação remunerada:

Art. 37. A administração pública direta e indireta de qualquer dos Poderes da União, dos Estados, do Distrito Federal e dos Municípios obedecerá aos princípios de legalidade, impessoalidade, moralidade, publicidade e eficiência e, também, ao seguinte:

$X V I$ - é vedada a acumulação remunerada de cargos públicos, exceto, quando houver

compatibilidade de horários, observado em qualquer caso o disposto no inciso $\mathrm{XI}$ :

a) a de dois cargos de professor;

b) a de um cargo de professor com outro técnico ou científico;

c) a de dois cargos ou empregos privativos de profissionais de saúde, com profissões regulamentadas;

A Constituição visou consagra o cargo de professor, permitindo o acúmulo juntamente com outros cargos públicos. 
Contudo, quando se trata de acumulação de três cargos remunerados, tem-se o exposto pela decisão da quinta turma do Superior Tribunal de Justiça:

PROVENTOS. ACUMULAÇÃO TRÍPLICE. CARGO PÚBLICO.

É ilegal a acumulação tríplice oriunda de dois cargos públicos com mais vencimentos relativos a um terceiro cargo público, ainda que a nomeação para o terceiro cargo tenha sido por aprovação em concurso público antes da EC $n$. 20/1998, pois extrapola o art. 37, XVI, da CF/1988. Entretanto o servidor terá direito de opção. Precedentes citados no STF: RE 141.376-RJ, DJ 22/2/2002; no STJ: AgRg no RMS 13.123-PR, DJ 22/4/2003; AgRg no RMS 15.008-PR, DJ 10/2/2003; RMS 14.173-PR, DJ 2/9/2002, e RMS 9.971-CE, DJ 14/2/2000. AgRg no RMS 14.937-PR, Rel. Min. Felix Fischer, julgado em 3/6/2003.

Em outra decisão, proferida pelo Supremo Tribunal Federal, não se admitiu a acumulação de três cargos públicos, mesmo sendo um deles contando com o servidor aposentado. Assim, tem-se um trecho do acórdão do Recurso Extraordinário de ํo 141.376/RJ:

Não resta, assim, dúvida quanto a manter o recorrido duas posições constitucionalmente acumuláveis e ainda uma terceira fonte de percepção de vencimentos. Detém dois cargos de médico e um de professor adjunto na UERJ. $O$ ato administrativo que afirmou a inviabilidade do tríplice acúmulo corresponde, destarte, a orientação do STF, no sentido de não ser possível a acumulação resultante de três posições no serviço público, ainda que, de referência a uma delas, esteja o servidor aposentado ou em processo de inativação. No caso, às fls. 39, está publicado o ato de aposentadoria do recorrido no cargo estadual de médico (...)

(...)

11. Como se vê, o impetrante não exercia cargos, funções ou empregos legalmente acumuláveis na atividade. $O$ fato de ter se aposentado em um dos cargos não lhe socorre, nem torna lícita a acumulação, que já era ilícita.

Assim como no caso anterior, um agravo regimental no agravo de instrumento, trouxe a discussão do caso em que houve a acumulação de duas aposentadorias de professor com vencimento de um terceiro cargo, neste caso antes da Emenda Constitucional no 20/98:

AGRAVO REGIMENTAL EM AGRAVO DE INSTRUMENTO. ADMINISTRATIVO. SERVIDOR PÚBLICO. MAGISTÉRIO. DE ACUMULAÇÃO DE PROVENTOS DE DOIS CARGOS DE PROFESSOR COM VENCIMENTOS 
DE UM TERCEIRO CARGO. ART. 11, DA EC 20/98. INAPLICABILIDADE. AGRAVO IMPROVIDO.

I - Somente se admite a acumulação de proventos e vencimentos quando se tratar de cargos, empregos ou funções acumuláveis em atividade, na forma prevista pela Constituição Federal. Precedentes.

II - Não é permitida a acumulação de proventos de duas aposentadorias com os vencimentos de cargo público, ainda que proveniente de aprovação em concurso público antes da EC 20/98. Precedentes.

\section{A acumulação de cargos públicos gerou a discussão em outros sentidos na} jurisprudência, como segue abaixo:

CONSTITUCIONAL. ADMINISTRATIVO. SERVIDOR PÚBLICO. PROFESSOR. TRIPLAACUMULAÇÃO DE CARGOS. INVIABILIDADE. TRANSCURSO DE GRANDE PERÍODO DETEMPO. IRRELEVÂNCIA. DIREITO ADQUIRIDO. INEXISTÊNCIA.

1. Esta Corte já afirmou ser inviável a tripla acumulação de cargos públicos.

Precedentes: RE 141.376 e Al 419.426-AgR.

2. Sob a égide da Constituição anterior, o Plenário desta Corte, ao julgar o RE 101.126, assentou que "as fundações instituídas pelo Poder Público, que assumem a gestão de serviço estatal e se submetem a regime administrativo previsto, nos Estados-membros, por leis estaduais são fundações de direito público, e, portanto, pessoas jurídicas de direito público". Por isso, aplica-se a elas a proibição de acumulação indevida de cargos.

3. Esta Corte rejeita a chamada "teoria do fato consumado". Precedente: RE 120.893-AgR 4. Incidência da primeira parte da Súmula STF no 473: "a administração pode anular seus próprios atos, quando eivados de vícios que os tornam ilegais, porque deles não se originam direitos".

5. O direito adquirido e o decurso de longo tempo não podem ser opostos quanto se tratar de manifesta contrariedade à Constituição.

6. Recurso extraordinário conhecido e provido.

Por este fato controvertido houve a exposição do que defendia Silva (1989, p. 185):

Seja-nos permitido lastimar, de logo, que os Srs. Constituintes não tivessem aproveitado a oportunidade para retirar a expressão "remunerada" que entrou inadvertidamente na Carta de 1967 e é de crer que, por mero capricho, foi mantida na Emenda no 1, de 17 de outubro de 1969. Mal souberam que vários juízes, mesmo federais, têm admitido legitimidade de situação quando o que acumula só percebe por um dos cargos, empregos ou funções, como na hipótese de licença em um deles, para tratamento de interesse particular. 
Cabe elencar também o caso do professor com dedicação exclusiva, que é proibido de receber outras remunerações, salvo exceções legais, como no caso exposto pelo artigo 20 da Lei ํㅜ 12.772 de 2012 :

Art. 20. O Professor das IFE, ocupante de cargo efetivo do Plano de Carreiras e Cargos de Magistério Federal, será submetido a um dos seguintes regimes de trabalho:

I - 40 (quarenta) horas semanais de trabalho, em tempo integral, com dedicação exclusiva às atividades de ensino, pesquisa, extensão e gestão institucional; ou (...)

$\S 20$ O regime de 40 (quarenta) horas com dedicação exclusiva implica o impedimento do exercício de outra atividade remunerada, pública ou privada, com as exceções previstas nesta Lei.

Durante considerável período de tempo, houve a dúvida sobre se poderia ocorrer a acumulação de cargo para professor com dedicação exclusiva, pois a Constituição Federal impôs apenas como requisito a compatibilidade de horário e que o teto fosse no máximo igual do Ministro do STF.

É fundamental expor o entendimento expresso pelo Supremo Tribunal Federal sobre 0 assunto:

MANDADO DE SEGURANÇA. ATO DO TRIBUNAL DE CONTAS DA UNIÃO QUE CONSIDEROU ILEGAL APOSENTADORIA E DETERMINOU A RESTITUIÇÃO DE TODOS VALORES. (...)

1. A compatibilidade de horários é requisito indispensável para o reconhecimento da licitude da acumulação de cargos públicos. É ilegal a acumulação dos cargos quando ambos estão submetidos ao regime de 40 horas semanais e um deles exige dedicação exclusiva.

2. $O \S 2^{\circ}$ do art. 193 da Lei n. 8.112/1990 veda a utilização cumulativa do tempo de exercício de função ou cargo comissionado para assegurar a incorporação de quintos nos proventos do servidor (art. 62 da Lei n. 8.112/1990) e para viabilizar a percepção da gratificação de função em sua aposentadoria (art. 193, caput, da Lei n. 8.112/1990). É inadmissível a incorporação de vantagens sob o mesmo fundamento, ainda que em cargos públicos diversos.

3. O reconhecimento da ilegalidade da cumulação de vantagens não determina, automaticamente, a restituição ao erário dos valores recebidos, salvo se comprovada a má-fé do servidor, o que não foi demonstrado nos autos.

(...)

6. Segurança parcialmente concedida 
Pela decisão acima, a ilegalidade da acumulação de cargo é evidente, não se pode acumular dois cargos de 40 horas semanais, sendo que um deles é de dedicação exclusiva. Contudo, por mais que seja ilegal, só seria punido com a restituição de valor caso fosse comprovada a má-fé do servidor.

Algo que é plenamente possível é exposto por Nelson (2016, p. 164) "um professor aposentado em regime de dedicação exclusiva de uma Universidade Federal, poderia, após prestar concurso público adentrar em um cargo de professor dedicação exclusiva de um Instituto Federal ou Universidade Estadual, por exemplo."

Deste modo, a aposentadoria pode ser cumulada com outro cargo público, sem nenhuma restrição.

Como ocorreu numa recisão do Superior Tribunal de Justiça, por meio de um agravo regimental no agravo em Recurso Especial no 548537/PE:

PROCESSUAL CIVIL E ADMINISTRATIVO. AGRAVO REGIMENTAL NO AGRAVO EM RECURSO ESPECIAL. PROFESSOR. DEDICAÇÃO EXCLUSIVA. CUMULAÇÃO COM OS PROVENTOS DE APOSENTADORIA ANTERIOR. POSSIBILIDADE.

1. A jurisprudência desta Corte entende ser possível a cumulação de proventos de professor decorrentes dos respectivos cargos em dedicação exclusiva, desde que tenham sido exercidos em períodos distintos pois, nessa hipótese, resta perfeitamente observado o requisito da compatibilidade de horários. Precedentes: AgRg no REsp 992.492/RJ, Rel. Ministro Napoleão Nunes Maia Filho, Quinta Turma, DJe 25/10/2010; REsp 872.503/RO, Rel. Ministra Laurita Vaz, Quinta Turma, DJe 29/11/2010; AgRg no AgRg no REsp 817168/RJ, Rel. Ministro Og Fernandes, Sexta Turma, DJe 3/8/2011.

2. Agravo regimental não provido.

$\mathrm{Na}$ mesma direção caminha a jurisprudência seguinte, proferida pelo Resp 872.503/RO de 2010 pelo STJ:

ADMINISTRATIVO. PROCESSUAL CIVIL. ANÁLISE DE DISPOSITIVOS CONSTITUCIONAIS. IMPOSSIBILIDADE NA VIA DO ESPECIAL. AFRONTA AOS ARTS. 131 165, 458, INCISO II, E 535, INCISO II, DO CÓDIGO DE PROCESSO CIVIL. OMISSÃO. ALEGAÇÃO GENÉRICA. SÚMULA N․ำ 284 DO SUPREMO TRIBUNAL FEDERAL. PROFESSOR. EXERCÍCIO DE 02 CARGOS DE DEDICAÇÃO EXCLUSIVA EM PERÍODOS DISTINTOS. APOSENTADORIAS.

CUMULAÇÃO. POSSIBILIDADE. REQUISITO DA COMPATIBILIDADE DE 


\section{ISSN no 2359-0106 Vol. 5, n.2, 2018.}

HORÁRIOS. ATENDIDO.

1. A via especial, destinada à uniformização da interpretação da legislação infraconstitucional, não se presta à análise de possível violação a dispositivos da Constituição da República.

2. Quanto à pretensa violação ao art. 535 do Código de Processo Civil, não tendo sido esclarecido de maneira específica, ponto a ponto, quais questões, objeto da irresignação recursal, não foram debatidas pela Corte de origem, incide, na hipótese, a Súmula n. -284 da Suprema Corte.

3. É possível a cumulação de 02 (dois) proventos de professor decorrentes dos respectivos cargos em dedicação exclusiva, caso esses tenham sido levados a efeito em períodos distintos, ou seja, desde que o exercício do segundo tenha ocorrido após a aposentação no primeiro, porquanto, nessa hipótese, resta perfeitamente observado o requisito da compatibilidade de horários.

4. Recurso especial parcialmente conhecido e, nessa extensão desprovido.

\section{Outro aspecto controverso é encontrado no que se refere a conversão do tempo}

exercido como professor, para muitos considerado como especial, em tempo de contribuição comum, conforme pode-se apurar abaixo, de acordo com Rocha e Baltazar Júnior (2003, p. 209-210):

Em sentido contrário, poderíamos esgrimir que a vedação só existiria para o regime dos servidores públicos, e não para o regime geral. A aposentadoria por tempo de serviço do professor nada mais é do que uma aposentadoria especial, ou seja, uma subespécie de aposentadoria por tempo de serviço, a qual exige um tempo de serviço reduzido em face das condições desgastantes em que é exercida. Com efeito, quando o Poder Executivo regulamentou as atividades insalubres, perigosas e penosas referidas no artigo 32 da LOPS, esta atividade integrava o elenco, situada no item 2.1.4 do rol do Decreto 53.831/64. Com o advento da Emenda Constitucional 18/81, este tipo de aposentadoria especial adquiriu "status" constitucional. Tanto a Consolidação das Leis da Previdência Social de 1976, bem como a de 1984 reconheciam este fato, incluindo este benefício no capítulo destinado às aposentadorias especiais. Sobrevindo a Constituição Federal de 1988, foi mantida a disciplina constitucional do benefício para o servidor público no inciso III do art. 40 e para os beneficiários do regime geral no inciso III do art. 202. Conquanto a Lei no. 8.213/91 não tenha disciplinado a aposentadoria por tempo de serviço do professor dentro da subseção que regula a aposentadoria especial, considerando a origem do benefício e o fato de a posição topográfica não se constituir em um critério determinante para a classificação de um determinado instituto jurídico, parece razoável classificá-la como uma modalidade de aposentadoria especial. Se concordarmos com esta conclusão, não havendo regra específica que proíba ou discipline de forma diversa a conversão do tempo de serviço neste benefício, aplicáveis são as regras comuns aos demais benefícios. Um esclarecimento, todavia, se impõe, considerando que o segurado professor faz jus ao benefício aos 30 anos, e não aos 25 , como na maior parte das atividades especiais, o 
fator de conversão a ser utilizado não pode ser o mesmo, cabendo o emprego do fator de 1,17 .

Deste modo, a conversão do tempo de contribuição é outro ponto importante, e é uma matéria que está pacificando mas ainda gera algumas controvérsias.

\section{CONCLUSÃO}

No cenário de incertezas no qual os brasileiros vivem atualmente, a reforma da previdência e, especialmente, a aposentadoria de professores é uma das que se destacam, pela especificidade deste tipo de aposentadoria, como tempo de contribuição e salário de benefício.

Este artigo refletiu sobre a aposentadoria dos professores de educação básica e a legislação previdenciária brasileira, que, em razão da sua função, contemplam um período menor para aposentar, tanto mulheres como homens.

A problemática que envolveu o presente trabalho foi a seguinte: quais são as peculiaridades da aposentadoria dos professores em comparação com a aposentadoria comum no regime geral da Previdência Social?

Diante disso, entende-se que realmente na atual legislação a aposentadoria de professor, independentemente de sexo, homens e mulheres contribuem 5 anos a menos do que outros tipos de profissão, com exceção das elencadas como especiais. Ademais, houve uma discussão jurisprudencial durante muito tempo sobre quais seriam os limites das atividades consideradas como a dos professores da educação básica.

\section{REFERÊNCIAS}

ANASPS. Evolução da Previdência Social. J. B. Serra e Gurgel (pesquisador). Brasília, 2007. Disponível em:

<http://www.anasps.org.br/evolucao_historica_previdencia.pdf>. Acesso em: 20.set.2018. 
BRASIL. Lei $\mathbf{n}^{\circ}$ 9.394, de 20 de dezembro de 1996e. Estabelece as diretrizes da educação nacional. Disponível em:

<http://www.planalto.gov.br/ccivil_03/leis/19394.htm>. Acesso em 20.set.2018.

. Lei no 8.213, de 24 de julho de 1991. Dispõe sobre os planos de benefícios da Previdência Social e dá outras providências. Disponível em:

<http://www.planalto.gov.br/ccivil_03/leis/L8213cons.htm>. Acesso em 20.set.2018.

. Constituição. 1988. Constituição da República Federativa do Brasil.

Disponível em: <http://www.planalto.gov.br/ccivil_03/constituicao/constituicao.htm>. Acesso em 20.set.2018.

Lei $\mathbf{n} . \mathbf{8}$ 8.213, de de 24 de julho de 1991. Dispõe sobre os Planos de Benefícios da Previdência Social e dá outras providências. Disponível em: http://www.planalto.gov.br/ccivil_03/Leis/L8213compilado.htm. Acesso em 20.set.2018.

. Emenda Constitucional no 20, de 15 de dezembro de 1998. Modifica arts. 37, 40, 42, 48, 96, 149 e 201 da Constituição Federal, revoga o inciso IX do §3 do art. 142 da Constituição Federal e dispositivos da Emenda Constitucional n²0, de 15 de dezembro de 1998, e dá outras providências.

Emenda Constitucional $\mathbf{n}^{\circ}$ 18, de 30 de junho de 1981. Dispõe sobre a aposentadoria especial para professores e professoras. Disponível em: <http://www.planalto.gov.br/cciVil_03/Constituicao/Emendas/Emc_anterior1988/emc1881.htm>. Acesso em 20.set.2018.

. Lei no 3.807, de 26 de agosto de 1960. Dispõe sobre a Lei Orgânica da Previdência Social.

. Lei no 10.666, de 8 de maio de 2003. Dispõe sobre a concessão da aposentadoria especial ao cooperado de cooperativa de trabalho ou de produção e dá outras providências. Disponível em:

<http://www.planalto.gov.br/ccivil_03/leis/2003/L10.666.htm>. Acesso em 20.set.2018.

. Decreto $\mathbf{n}^{\circ} \mathbf{5 3 . 8 3 1}$, de 25 de março de 1964. Dispõe sobre a aposentadoria especial instituída pela Lei 3.807, de 26 de agosto de 1960.

. Supremo Tribunal Federal. Súmula 726. Disponível em: <http://www.stf.jus.br/portal/jurisprudencia/menuSumarioSumulas. asp?sumula=1498>. Acesso em 20.set.2018. 
. Lei no 9.394, de 20 de dezembro de 1996. Estabelece as diretrizes e bases da educação nacional. Disponível em: <http://www.planalto.gov.br/ccivil_03/leis/19394.htm>. Acesso em 20.set.2018.

. Lei $\mathbf{n}^{\circ} \mathbf{1 2 . 7 7 2}$, de 28 de dezembro de 2012. Dispõe sobre a estruturação do plano de carreiras e cargos de magistério federal. Disponível em: <http://www.planalto.gov.br/ccivil_03/_ato2011-2014/2012/lei/12772.htm>. Disponível em: 20.set.2018.

. Supremo Tribunal Federal. ADIN no 3.772 Distrito Federal. Disponível em: < http://redir.stf.jus.br/paginadorpub/paginador.jsp?docTP=AC\&doc/D $=605033>$. Acesso em 20.set.2018.

\section{em:}

. Supremo Tribunal Federal. Recurso extraordinário no 141.376/RJ. Disponível <http://www.stf.jus.br/portal/jurisprudencia/visualizarEmenta.asp?s1=000031919\&base= basePresidencia>. Acesso em: 20.set.2018.

. Superior Tribunal de Justiça. Recurso especial no 548537/PE. Disponível em: <https://stj.jusbrasil.com.br/jurisprudencia/178138719/agravo-regimental-no-agravo-emrecurso-especial-agrg-no-aresp-548537-pe-2014-0181355-1/relatorio-e-voto178138751 ? ref $=$ serp $>$. Acesso em 20.set.2018.

. Superior Tribunal de Justiça. Recurso Especial no 872503/RO. Disponível em: <https://stj.jusbrasil.com.br/jurisprudencia/17675590/recurso-especial-resp-872503-ro2006-0175633-8-stj/relatorio-e-voto-17692119?ref=serp>. Acesso em: 20.set.2018.

CASTRO, Carlos Alberto. Manual de Direito Previdenciário. 5. Ed. São Paulo: LTR, 2004.

; LAZZARI, João Batista. Manual de direito previdenciário. 15. ed. rev. e atual. Rio de Janeiro: Forense, 2013.

MARTINEZ, Wladimir Novaes. Curso de direito previdenciário. 3ª ed. São Paulo: LTr, 2010.

NELSON, Rocco Antonio Rangel Rosso. Da regra constitucional da acumulação de cargos de professor no ordenamento jurídico brasileiro. Revista de la facultad de ciencias económicas, n. 17, 149-168. Disponível em:

<http://revistas.unne.edu.ar/index.php/rfce/article/viewFile/1566/1337>. Acesso em 20.set.2018. 
ROCHA, Daniel Machado da; BALTAZAR JÚNIOR, José Paulo. Comentários à lei de benefícios da previdência social. 3 ed. rev. atual. Porto Alegre: Livraria do Advogado: Esmafe, 2003, p. 209-210.

SANTOS, Marisa Ferreira dos. Direito previdenciário esquematizado. $2^{2}$ ed. rev. e atual. São Paulo: Saraiva, 2013.

SILVA, C. M. O regime de acumulação na Constituição de 1988. 1989. Revista de Informação Legislativa, 26, n. 101, 183-196. Disponível em:

<http://www2.senado.leg.br/bdsf/item/id/181913>. Acesso em 20.set.2018 